\title{
A Comparison of the First and Second Languages of American and Spanish Students ${ }^{1}$
}

\author{
Klaus F. Riegel, Robert M. Ramsey, ${ }^{2}$ and Ruth M. Riegel \\ University of Michigan, Ann Arbor, Michigan
}

\begin{abstract}
Twenty-four American and 24 Spanish Ss gave restricted associations both in English and in Spanish to 35 stimuli under seven different instructions. Secondlanguage learners left more blanks in their records than native speakers. This was particularly true for American Ss studying Spanish. In both languages, the response variability was greater for Spanish than for American Ss. However, American Ss were superior when the degree of conceptual clarity was analyzed by counting the response repetitions per stimulus that occur under different task instructions. Interpretations were given in terms of growth of vocabulary and in terms of the acquisition of the conceptual, semantic systems of the target language.
\end{abstract}

Several studies of bilingual children in Spanish-American and other mixed linguistic environments have been reported (McCarthy, 1954). However, bilingualism acquired under more formal training procedures, as in high school or college settings, has seldom been investigated. Among the few attempts are those by Scherer and Wertheimer (1964), on second learning of German, and by Delattre (1947) on second learning of French. In these studies modifications in the training techniques were also investigated.

In a number of less ambitious studies, comparisons of verbal associations and habits have been made between different languages as well as between the languages of bilinguals. At the present time, word associations of American $S$ s have been compared with those of Navaho Indians (Ervin and Landar, 1963), Italians (Levi, 1949), Germans and Frenchmen (Russell

1 This study was supported by Grant MH 07619 from the United States Public Health Service.

${ }^{2}$ Now at Institute of North American Studies, Via Augusta 123, Barcelona, Spain. and Merck, 1959), German, Frenchmen and Italians (Rosenzweig, 1961), French children (Rosenzweig and Menahem, 1962), and French students and workmen (Rosenzweig, 1964). Rosenzweig (1957) also compared clustering in recall of French and American Ss. Studies of English-speaking bilinguals include those on color naming by Navaho Indians (Ervin, 1961b) and picture naming by Italians (Ervin, 1961a), as well as continuous associations (Lambert, 1956), reaction times to verbal instructions (Lambert, Havelka and Gardner, 1959), and semantic differential ratings of French-Canadians (Lambert, Havelka, and Crosby, 1958).

In a study quite similar to ours, Kolers (1963) compared three groups of bilinguals (German, Spanish, and Thai) on wordassociation tests. Four test sequences were analyzed: stimuli in English and in translations, responded to in English and in the native languages. About one-third of the responses in one language could be translated in the others. This result was obtained both on an intra- and an interlingual basis, but there was not much vari- 
ation in this percentage across languages. When the stimuli denoted concrete objects the percentages increased rather markedly, pointing perhaps, to a core of common non-linguistic experiences acquired by native speakers of different languages.

Kolers' study as well as the preceding ones represent comparisons of particular responses and of the response variabilities across languages. In the present investigation attempts will be made to compare also the conceptual semantic structure which presumably underlies and determines the various responses produced by bilinguals. The method to be used involves several types of restricted or controlled associations which allow not only for comparisons of the number and types of responses between the languages, but also for comparisons of the amount of interrelation among various response classes, and thus, of the degrees of conceptual semantic differentiation. Comparisons will be made between first- and second-language learners, and between the Spanish and the English language. Since at the present time little is known about the psycholinguistic mechanisms of first- and second-language learning, the primary purpose of the present investigation is descriptive.

\section{Method}

Twenty-four native English speakers and 24 native Spanish speakers participated in the experiment. The first group consisted of 18 females and 6 males whose average age was 19.4 years, and who were primarily from the Middle Western United States and were all undergraduates at the University of Michigan in a moderately advanced (5th semester level) Spanish course. Twelve males and 12 females participated as the native Spanish speakers. The males were, for the most part, graduate students at the University of Michigan and the females were their wives. Their average age was 25.4 years. Divided according to dialect areas, ten were from Venezuela, five from Argentina, three from Costa Rica, and two each from Cuba, Mexico, and Spain. All Ss were asked to rate their second language proficiency.
The following four categories were used: poor (1), fair (2), good (3), and excellent (4). Spanish Ss evaluated their proficiency at 2.5 and the American Ss at 2.2.

All Ss took two tests, one in their native language, the other in their second language. The order of the tests was counterbalanced. At least three weeks elapsed between the two administrations. No time pressure was exerted on the Ss. Each test consisted of seven pages of 35 stimuli, all of which were common nouns selected from the Kent-Rosanoff word association test (1910) and pretested on groups of 24 Ss each of first and second speakers of Spanish, and 168 native speakers of English. Seven tasks were randomly assigned to the pages. Two test forms were used in Spanish. Each form was administered to twelve randomly selected Ss. The two forms differed in that they each included a different member of the five pairs of synonyms as stimuli given at the end of the following list:

table-mesa, man-hombre, mountainmontaña, house-casa, hand-mano, fruitfruta, butterfly-mariposa, chair-silla, woman-mujer, river-rio, window-ventana, spider-araña, carpet-alfombra, girlchica, soldier-soldado, cabbage-col, lamp-lámpara, bread-pan, sheep-oveja, cottage-casita, head-cabeza, whiskeywhiskey, child-niño, thief-ladrón, bedcama, tobacco-tobaco, moon-luna, streetcalle, king-rey, cheese-queso, stomachestómago-barriga, boy-chico-muchacho, city-ciudad-pueblo, square-cuadradoplaza, doctor-doctor-medico.

The following are the instructions for the seven tasks of the English version of the test:

Superordinates:

Find a class-name for the stimulus. For instance, class-names for the word FORK are: SILVERWARE or UTENSIL. Classnames for the word LIMOUSINE are: CAR or VEHICLE.

Coordinates:

Name another member of the class to which the stimulus belongs. For instance, SPOON and KNIFE belong to the same class as FORK. TRAIN or BIKE belong to the same class as CAR. Similars:

Find a word that means essentially the same as the stimulus. For instance RAKE or BRANCH may be regarded as similars to FORK. AUTO or AUTO- 
MOBILE may be regarded as similars to CAR.

Contrasts:

Find a word that means essentially the opposite of the stimulus. For instance KNIFE or SPOON may be regarded as contrasts to FORK. FOOLISHNESS or STUPIDITY may be regarded as contrasts to WISDOM.

Functions:

Find a word that denotes the usage of the stimulus. For instance a FORK is used to EAT or TAKE-UP. CAR is used to TRAVEL or DRIVE.

Qualities:

Find a word that denotes a quality of the stimulus. For instance a FORK is POINTED or HEAVY. A CAR is FAST and SHINY.

Parts:

Name an essential part or attribute of the stimulus. For instance essential parts of a FORK are the HANDLE or the METAL. Essential attributes of WISDOM are EXPERIENCE and MATURITY.

The examples used in the instructions have been empirically developed by asking 12 American students for two restricted associations each to a list of stimuli including those used in the instructions (FORK, CAR, and WISDOM) but without providing any examples. The two responses most commonly given for each task have been used in the above instructions. The Spanish stimuli and instructions are translations of the English test prepared by four college teachers of Spanish.

\section{Results and Discussion}

Blanks. The S's failure to respond is indicative of his difficulty in following specific instructions for specific stimuli. However, the instructions provide only general directions and do not prevent a $S$ from choosing responses that are only remotely related to the stimuli. Thus, S's failure to respond is also indicative of the limits he himself has imposed upon his performance.

Generally, one would expect secondlanguage learners to leave more blanks than native speakers. Students of Spanish do indeed produce about seven times as many blanks (21.7\%) and second-language learners of English about five times as many blanks $(7.0 \%)$ as native speakers of Spanish $(3.0 \%)$ and English (1.3\%), respectively. Since the second learners of English judged their proficiency as higher than the second learners of Spanish, one would expect a greater number of blanks for the latter. Second learners of Spanish. do leave about three times more stimuli unanswered than second learners of English. Since the same relationship was found for the native speakers, however, this result may reflect differences between the languages rather than differences in proficiency between the second-language learners.

The observed differences in the number of blanks interact with the types of tasks. Except for the native speakers of English when responding in English, Ss had the greatest difficulty with Similars. The native speakers encountered further difficulties only with Contrasts and Superordinates and left less than $1 \%$ blanks on each of the remaining tasks. In comparison, the number of blanks is higher and the blanks are more equally distributed over all tasks for the second-language learners.

Types. Similar to the number of blanks, the number of different words (types) a person uses is indicative of his task attitude, his vocabulary, and also possible differences between languages. This index is much more complex, however, than the number of blanks in his records.

First, the number of different responses is dependent upon the type of restrictions imposed in the tasks. Thus, in some cases many appropriate responses, such as words denoting qualities, may be available in a language. The same result can also be produced, however, when the number of appropriate responses, such as contrastwords, is small. In this case most Ss use 
less appropriate responses, a behavior which yields many different responses, coupled with large numbers of blanks. Second, the number of different responses is dependent upon the sample size of words and/or Ss. Generally, the relative number of different responses, the type-token-ratio, decreases with increasing sample size. Therefore, if many Ss fail to respond, the type-token-ratio ought to be relatively high and comparisons between subgroups may be misleading.

In view of these difficulties, it is justifiable only to make comparisons between the total groups of American and Spanish Ss, on the one hand $(11.5 \%$ and $5.0 \%$ blanks, respectively), and between speakers of English and Spanish on the other ( $4.2 \%$ and $12.3 \%$ blanks, respectively). As shown in Table 1 , the numbers of different responses are higher for Spanish than for American Ss. Overall differences between the languages are not indicated. The average number of different responses is 10.4 for Spanish and 9.9 for English. This result seems to contradict the findings of Rosenzweig (1964), who reported higher commonality and thus presumably lower type-token-ratios for American as compared with French Ss. It should be noted, however, that in our comparisons first- and second-language learners have been pooled.
Since the number of blanks varies across tasks, analyses of variance were carried out on the number of different responses to the seven tasks separately. A significant language effect was found for the Coordinates only $(p<.05)$. The groups of Spanish and American $S s$ differed significantly $(p<$ .01) on all tasks except the Parts. The American Ss produced lower numbers of different responses than the Spanish on all significant tasks. Since both groups of Ss provide data on both languages, this result indicates that either American students of Spanish or Spanish students of English, or both, have failed to approach their target languages sufficiently well.

Group Overlaps. More complete measures of the success in learning a second language can be obtained by enumerating those responses given by both the first- and second-language learners to a particular task and stimulus. In such a comparison three statistics can be derived, none of which is seriously affected by differences in the number of responses. The first has been previously applied by Rosenzweig (1964) and enumerates the number of identical responses given by both groups. This measure is called minimum group overlap, MGO. The second includes those responses given by both groups, but is based upon the frequencies of the native speakers. This measure is called first-language group overlap, first GO. The third measure is the same as the second, but it lists the frequencies of the second-language learners. This measure is called second-language group overlap, second GO.

The following simplified example will clarify

TABLE 1

\begin{tabular}{lcccc}
\multicolumn{5}{c}{ Number of Drfferent } \\
\hline Tasks & $\begin{array}{c}\text { 1st Span. } \\
\text { (Span. Ss) }\end{array}$ & $\begin{array}{c}\text { 1st Engl. } \\
\text { (Amer. Ss) }\end{array}$ & $\begin{array}{c}\text { 2nd Span. } \\
\text { (Amer. Ss) }\end{array}$ & $\begin{array}{c}\text { 2nd Engl. } \\
\text { (Span. Ss) }\end{array}$ \\
\hline Superordinates & 12.7 & 8.3 & 7.6 & 11.2 \\
Coordinates & 12.0 & 8.3 & 8.9 & 9.3 \\
Similars & 11.8 & 8.6 & 7.7 & 9.5 \\
Contrasts & 9.9 & 8.0 & 7.4 & 8.7 \\
Functions & 11.4 & 8.4 & 7.6 & 9.7 \\
Qualities & 16.3 & 13.3 & 10.9 & 15.0 \\
Parts & 11.1 & 9.3 & 10.7 & 10.9 \\
Average & 12.2 & 9.2 & 8.7 & 10.5 \\
\hline
\end{tabular}


the measures: If the word TABLE is given eight times by the first- and five times by the secondlanguage learners as a Coordinate to the stimulus CHAIR, and the response BED occurs three times among the first- and four times among the second-language learners, then the minimum group overlap (MGO) is $5+3=8$; the firstlanguage group overlap (first $\mathrm{GO}$ ) is $8+3=11$; and the second-language group overlap (second $\mathrm{GO}$ ) is $5+4=9$.

In comparison, it is of interest to study those overlapping responses in each group that are not accounted for by the minimum group overlap. These responses can be derived by subtractions: (first $\mathrm{GO})-(\mathrm{MGO})=\mathrm{A}$. Here, A represents the overlapping responses by the first-language learners not accounted for by the minimum group overlap, i.e., responses to be incorporated at higher frequencies into the repertoires of the second-language learners for a good approximation of the target language. The overlapping responses by the second-language learners not accounted for by the minimum group overlap are given by ( second $\mathrm{GO})-(\mathrm{MGO})=\mathrm{C}$, and represent "over approximations," i.e., responses which are used by second-language learners more frequently than by the native speakers. These frequencies should be reduced for a good approximation of the target language. Finally, B represents those responses that are not yet used by the second-language learners at all, and $\mathrm{D}$ those that are used only by the second-language learners. Both $\mathrm{B}$ and $\mathrm{D}$ can be derived by subtracting MGO and A (or C) from $100 \%$, and should be reduced to zero for perfect approximations of the target languages.

The second learners of Spanish again were found to be less proficient than the second learners of English. As shown in Table 2, the average minimum group overlap, MGO, is only $28.5 \%$ for students of Spanish, but $44.4 \%$ for students of English. Moreover, the percentages of words that occur already, but not as frequently as for the native speakers, $A$, are only $10.1 \%$ for the second learners of Spanish, but $22.2 \%$ for the second learners of English. This brings the total percentages of words that are already in the repertoire of the second-language learners and are also used as responses by the native speakers to $38.6 \%$ for Spanish and to $66.6 \%$ for English. Hence, second learners of Spanish have to acquire $61.4 \%$ new items, B, but those of English only $33.4 \%$.

Rather marked differences in the responses exist among the different tasks. Second learners of Spanish deviate most strongly from native speakers on Similars and Qualities. Both MGO and the percentages of responses already acquired but used too rarely, A, are low, and thus the percentages of responses not yet acquired, $\mathrm{B}$, are above $70 \%$. In comparison, MGO for Parts is also low, but since set $A$ is relatively large, learning has progressed much further and the percentage of responses not yet acquired is but $58.8 \%$. Most progress has been made on the Contrasts where only $47.2 \%$ new responses have to be acquired and where MGO, is already very high $(42.6 \%)$.

The second learners of English are most de-

TABLE 2

Measures of Grocy Overlaps (GO) in Percentages ${ }^{a}$

\begin{tabular}{|c|c|c|c|c|c|c|c|c|}
\hline \multirow[b]{2}{*}{ Tasks } & \multicolumn{4}{|c|}{ Spanish } & \multicolumn{4}{|c|}{ English } \\
\hline & MGO & $\mathbf{A}$ & $\mathbf{B}$ & $\mathrm{C}$ & MGO & $\mathbf{A}$ & B & C \\
\hline Superordinates & 25.8 & 9.9 & 64.3 & 16.2 & 39.0 & 30.2 & 30.8 & 7.7 \\
\hline Coordinates & 31.1 & 9.9 & 59.0 & 19.9 & 52.1 & 20.3 & 27.6 & 12.8 \\
\hline Similars & 21.9 & 7.8 & 70.3 & 14.3 & 44.6 & 27.1 & 28.3 & 14.0 \\
\hline Contrasts & 42.6 & 10.2 & 47.2 & 8.2 & 52.9 & 19.2 & 27.9 & 10.5 \\
\hline Functions & 34.7 & 5.6 & 59.7 & 23.7 & 46.1 & 22.0 & 31.9 & 13.4 \\
\hline Qualities & 22.7 & 6.8 & 70.5 & 17.0 & 29.5 & 18.5 & 52.0 & 8.1 \\
\hline Parts & 20.4 & 20.8 & 58.8 & 8.1 & 47.6 & 17.1 & 35.3 & 8.5 \\
\hline Average & 28.5 & 10.1 & 61.4 & 15.3 & 44.4 & 22.2 & 33.4 & 10.8 \\
\hline
\end{tabular}

a For explanations of the abbreviations see text. Briefly, MGO = items already acquired by second language learners; $\mathbf{A}=$ items already acquired, but to be used more often; $\mathrm{B}=$ items not yet used; $\mathrm{C}=$ items used too frequently; and $D$ (not given in the Table) = items not to be used any longer. Both MGO $+\mathrm{A}+\mathrm{B}$ and $\mathrm{MGO}+\mathrm{C}+\mathrm{D}$ equal $100 \%$. 
layed in their acquisition of Quality responses but have progressed well on the Similars for which, in particular, MGO is relatively high $(44.6 \%)$. They are furthest advanced on Coordinates and Contrasts which are closely followed by the Similars. In these three tasks only about $28 \%$ of the responses of the native speakers are not yet part of the repertoire of the second language learners.

Task Overlaps. Many Ss are unable to react to a given stimulus with a different response under all different task instructions. Most Ss repeat themselves, and the amount of response repetition is a function of their acquired language proficiency and conceptual clarity, as well as of characteristics of the language in which they reply. The amount of response repetition is high for young as well as for less educated Ss, and decreases with age and education, (Riegel, Riegel, Smith, and Quarterman, 1964). In the present investigation we should expect a greater amount of response repetition (task overlap) for secondthan for first-language learners.

The response repetitions are enumerated by counting the number of identical responses given to the same stimulus under the seven instructions. In a forthcoming report it will be shown that the amount of task overlap correlates very little with the number of different responses given, and even less with the number of blanks. Our enumeration provides one half of a seven-by-seven matrix. In the present analysis we will, however, disregard the single overlaps between any two tasks and restrict ourselves to the sum of overlaps of any one task with the remaining six. Figure 1 presents the sums of overlaps per $S$ and stimulus multiplied by 100 .

Differences in the sums of overlaps between the native speakers of both languages were observed. Native speakers of English show greater overlaps than those of Spanish on tasks of logical relations or verbal abstractions, namely Coordinates, Contrasts and Similars. Qualities, Functions, and Parts denote physical conditions of the object or events named by the stimuli. Here, native speakers of English have lower overlaps and thus show greater conceptual clarity. Similar results were obtained for the second-language learners. However, their sums of overlaps are generally higher than for native speakers.

Comparisons between the first- and secondlanguage learners within each language reveal close approximations of the conceptual structures of the target languages by the second learners of Spanish except for Coordinates, Similars and Contrasts. Second learners of English seem, however, to "overapproximate" their target language by producing much higher overlap coefficients on all tasks, and thus a less satisfactory conceptual match. These results should be compared with the response variabilities where the students of English, but not those of Spanish, approximate quite closely their target language. Apparently, Spanish Ss have acquired a richer vocabulary in English than American Ss in Spanish, but fail to approximate as well the conceptual, verbal structure of their target language. This result may partially be explained by the greater amount of
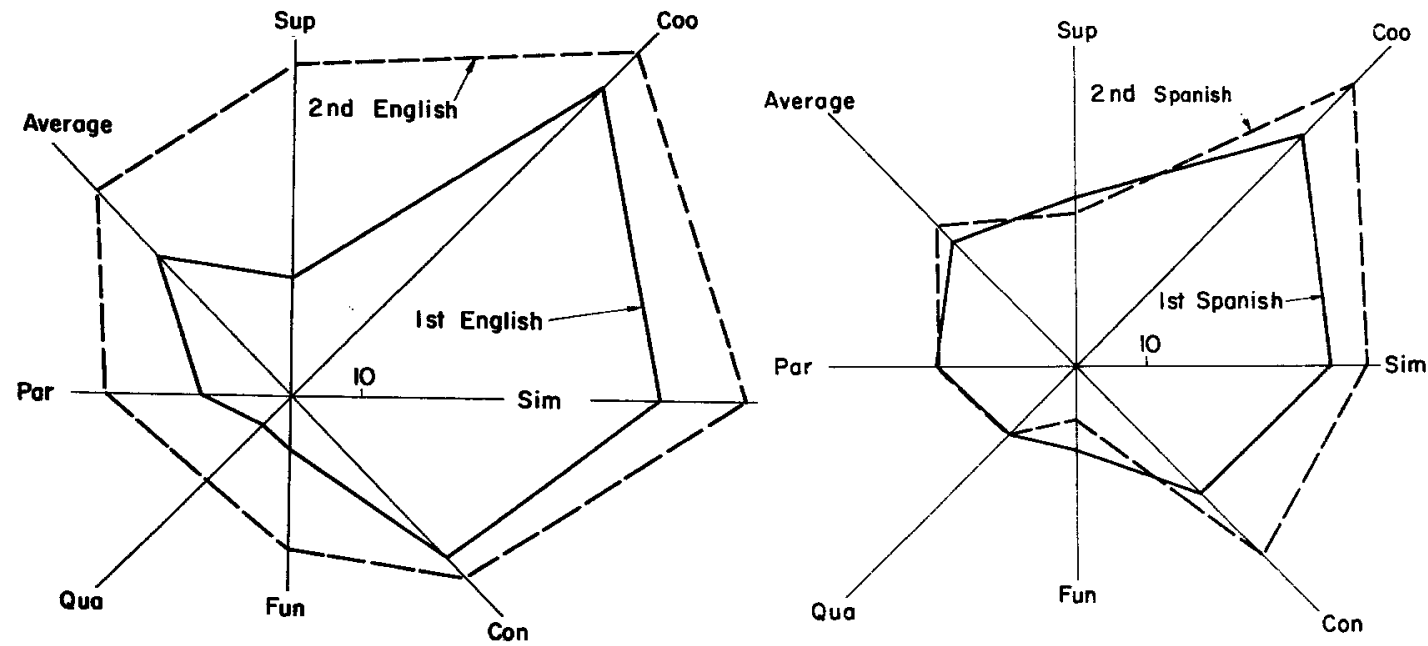

Frg. 1. Sums of overlaps between any single task and the remaining six for first and second learners of Spanish and English. 
formal training received by the second learners of Spanish. The second learners of English represent a more heterogeneous group and their strength lies in their ability to converse in English. Many of them acquired their English language ability during active communications with Americans in this country, without, or with little, formal training.

Our interpretations are supported by a correlational analysis of the overlap coefficients of the complete overlap matrices for the tasks. First, the correlation between the two languages is lower when the native speakers (.55) rather than the second-language learners (.63) are compared. Apparently, the native language interferes with the responses of the second language but not vice versa. Second, American students approximate the Spanish of native speakers more closely (.68) than Spanish students approximate the English of Americans (.52). Third, the same result is revealed by the lower correlation of the second learners of Spanish with their native English (.46) in comparison to the second learners of English with their native Spanish (.79).

Analyses of variance were carried out for the seven tasks separately. Significant language effects $(p<.01)$ were found for Superordinates, Coordinates, and Similars. Group effects were significant for Superordinates and Functions $(p<.01)$ and for Parts $(p<.05)$. The interactions were significant for all tasks.

Shared Responses to Alternate-Translated Stimuli. For the translation of five English stimuli, two alternate words were used in Spanish which were each given to half of the Ss. Intuitively, some of these alternate-translated stimuli appear to be close synonyms, while others differ in meaning. The purpose of this part of our investigation was to evaluate the substitutability of the alternate stimuli and to determine whether the substitutability varies with levels of language proficiency.

Table 3 lists the number of blanks and the number of shared responses given by both groups of $12 \mathrm{Ss}$ to the five pairs of stimuli. As in the main part of our study, second language learners of Spanish leave about eight times as many blanks as native speakers. In particular, some words do not seem to be sufficiently known to the second-language learners, namely BARRIGA and CUADRADO.

TABLE 3

Numbers of Blanks and Percentages of Shared Responseg to Related Stimuli by Stimulus Pairs, Tasks, and Groups of Tasks

\begin{tabular}{|c|c|c|c|c|}
\hline & \multicolumn{2}{|c|}{ Blanks ${ }^{a}$} & \multicolumn{2}{|c|}{ Shared Rs } \\
\hline & Ist & 2nd & 1st & end \\
\hline Doctor/Medico & $1 / 1^{b}$ & $4 / 8$ & 38.4 & 42.3 \\
\hline Chico/Muchacho & $2 / 3$ & $6 / 7$ & 20.5 & 31.0 \\
\hline Ciudad/Pueblo & $1 / 1$ & $3 / 7$ & 21.9 & 22.5 \\
\hline Estomago/Barriga & $2 / 6$ & $17 / 74$ & 17.8 & 2.8 \\
\hline Cuadrado/Plaza & $3 / 5$ & $64 / 16$ & 1.4 & 1.4 \\
\hline Superordinates & 3 & 27 & 19.2 & 14.1 \\
\hline Coordinates & 3 & 23 & 4.1 & 9.9 \\
\hline Similars & 8 & 39 & 19.2 & 12.7 \\
\hline Contrasts & 4 & 32 & 15.1 & 5.6 \\
\hline Functions & I & 25 & 26.0 & 29.6 \\
\hline Qualities & 2 & 32 & 8.2 & 14.1 \\
\hline Parts & 4 & 28 & 8.2 & 14.1 \\
\hline Logical & 18 & 121 & 57.6 & 42.2 \\
\hline Infralogical & 7 & 85 & 42.4 & 57.8 \\
\hline
\end{tabular}

a Given by 12 Ss to seven tasks or five stimuli, respectively.

$b$ The first figure refers to the first stimulus; the second to its alternate translation. 
The percentages of shared responses were determined by counting for each task the numbers of identical responses given by the two groups of $12 \mathrm{Ss}$. Shared responses to a particular pair of stimuli but in nonidentical tasks were disregarded in the analysis. The percentages of shared responses represent lower-bound estimates like the minimum group overlap, MGO. If the other stimulus of each pair appeared as a response, which is particularly likely for the Synonyms, it was included in the analysis as a shared response.

On the average, second-language learners produced as many shared responses as the native speakers, namely 14.2 and 14.6, respectively. For both groups of $S s$, the pair DOCTOR/MEDICO shared the greatest, and the pair CUADRADO/ PLAZA the smallest number of responses. The percentages of the second-language learners are higher than those of the native speakers for the first three pairs of stimuli, i.e., for those words that are sufficiently known to them. This indicates again a lower degree of response differentiation by the second-language learners. The low percentages of shared responses given by second-language learners to the last two pairs of stimuli have to be explained by their lack of familiarity with BARRIGA and CUADRADO. However, for the pair CUADRADO/PLAZA, the percentage is equally low for the first-language learners, indicating also the presence of a distinct meaning for each of the Spanish terms in comparison to the double meaning of the English equivalent (SQUARE).

Except for the Coordinates, native speakers have higher percentages of shared responses on the logical tasks and secondlanguage learners on the infralogical tasks. Thus, for the native speakers, similarity in word meaning implies high percentages of shared responses that are members of abstract verbal classes. For second-language learners, however, similarity in meaning implies common functions, qualities, and parts of the objects or events denoted by the stimuli.

\section{Conclusions}

The present investigation was based on the assumption that second-language learning should result not only in an increase in vocabulary, but also in an approximation to the conceptual semantic structure of the target language. The methodology of restricted or controlled word associations seems appropriate for an analysis of both these aspects of language proficiency.

Differences in the verbal habits of native speakers of Spanish and English were detected. In particular, native speakers of English display less clear conceptual distinctions between responses denoting Coordinates, Contrasts, and Similars than native speakers of Spanish. They separate more clearly, however, responses denoting Parts, Qualities, or Functions. The conceptual distinctions of second languages are less clear than those of native speakers.

Surprisingly, the retardation in conceptual distinctions was particularly marked for the English of the Spanish Ss who on all simpler measures approximated their target language much better than American Ss studying Spanish. On the other hand American students were very sensitive to reducing or increasing their response overlaps in approximating the target language, whereas Spanish students increased indiscriminately the overlaps on all tasks. If we compare the observed performances with results obtained on the same tasks from Ss differing in educational levels and age (Riegel, Riegel, Smith and Quarterman, 1964), we find that in conceptual clarity the Spanish of American Ss resembles closely the English of American college students, whereas the English of Spanish Ss 
corresponds more closely to that of American 6th graders.

The discrepancy between our results on response variability (blanks, types, and group overlaps) and on the task overlaps implies that it is insufficient to evaluate the progress in second-language learning by enumerating the number and variation of vocabulary items. Quite obviously, grammatical knowledge has to be tested andpossibly not as obviously-the apprehension and utilization of the conceptual semantic structure of the target language. In showing differences in the conceptual clarity between the two languages and the two national groups, we have moved from a loworder analysis of isolated items (words) to the study of word classes and word and class relations (Riegel and Riegel, 1963).

Since Spanish Ss had less formal secondlanguage training than the Americans, but had acquired their English primarily during active, daily communication in an American environment, our findings are also suggestive for comparisons of training and teaching procedures. Apparently formal language training in college settings encourages the identification of the conceptual semantic structure of the target language, whereas the informal training in everyday communications leads to a fast increase in the vocabulary and in verbal fluency.

\section{REFERENCES}

Delattre, P. A technique of aural-oral approach: report on a University of Oklahoma experiment in teaching French. French Rev., 1947, 20, 238-250, 311-324.

Ekvin, Susan M. Learning and recall in bilinguals. Amer. J. Psychol., 1961, 74, 446-451. (a)

Ervin, Susan, M. Semantic shift in bilingualism. Amer. J. Psychol., 1961, 74, 233-241. (b)

Ervin, Susan M., and Landar, H. Navaho word associations. Amer. J. Psychol., 1963, 76, 4957.

Kent, Grace H., and Rosanoff, A. S. A study of association in insanity. Amer. J. Insanity, $1910,67,37-96,317-390$.
Kolers, P. A. Interlingual word associations. J. verb. Learn. verb. Behav., 1963, 2, 291-300.

LAMbERT, W. E. Developmental aspects of secondlanguage acquisition: I. Associational fluency, stimulus provocativeness and word-orderinfluence. J. soc. Psychol., 1956, 43, 83-89.

Lambert, W. E., Havelka, J., and Crosby, C. The influence of language-acquisition contexts on bilingualism, J. abnorm. soc. Psychol, 1958, 56, 239-244.

Lambert, W. E., Hayelka, J., and Gardner, R. C. Linguistic manifestations of bilingualism, Amer. J. Psychol., 1959, 72, 77-82.

Levi, M. An analysis of the influence of two different cultures of responses to the Rosanoff Free Association Test. Unpublished Master's Thesis, University of Chicago, 1949.

McCarthy, Dorothea. Language development in children. L. Carmichael (Ed.), Manual of Child Psychology, New York: Wiley, 1954. Pp. 492-630.

Riegel, K. F., And Riegel, Ruth M. An investigation into denotative aspect of word meaning. Lang. Speech, 1963, 6, 5-21.

Riegel, K. F., Rregel, Ruth M., SMrth, Helen E., and Quarterman, Carole J. An analysis of differences in word meaning and semantic structure between four educational levels. Rep. No. 2, USPHS Grant MH 07619 , University of Michigan, 1964.

Rosenzweig, M. R. Etudes sur les associations des mots. Année Psychol., 1957, 1, 23-32.

Rosenzweig, M. R. Comparisons among word association responses in English, French, German and Italian. Amer. J. Psychol, 1961, 74, 347-360.

Rosenzweig, M. R. Word associations of French workmen: Comparisons with associations of French students and American workers and students. J. verb. Learn. verb. Behav., 1964 , $3,57-69$.

Rosenzweig, M. R., and Menahem, R. Age, sexe et niveau d'instruction comme facteurs déterminants dans les associations des mots. Année Psychol., 1962, 62, 45-61.

Russell, W. A., And Merck, O. R. Der Einfluss der Assoziation auf das Erinnern von Worten in der deutschen, französischen und englischen Sprache. Z. exp. angew. Psychol., 1959, 6, 191-211.

Scherer, G. A. C., and Wertheimer, M. A psycholinguistic experiment in foreign-language teaching, New York: McGraw-Hill, 1964.

(Received October 18, 1965) 